\title{
Global Warming and Food Engineering Emissions
}

\author{
Kolawole Oladele Peter \\ Agricultural Engineering, Federal University of Technology Akure / FMS International Institute of Tropical Agriculture (IITA) Ibadan \\ Nigeria
}

\begin{abstract}
Pollution is the cause of global warming; this was linked with the world energy poverty, many countries of the world dependent on generators for electricity was blamed on inadequate clean energy supply. Food industries still depend on fossil fuels to power farm tractors and vehicles. Other developing nation's dependant on fire woods leads to deforestation. Global warming is here, the bad effect is already happening, mostly the world's poorest people are feeling the impact. Combustion processes in heat engines as one of the leading causes are not checkmated; gases from combustion of carbon compounds burns in oxygen, nitrogen and Carbon among others are major pollutants. Nitrogen yields nitrogen dioxide and Carbon yields carbon dioxide these are the pollutants playing major role in global warming. This is threatening human progress and making the United Nations' Millennium Development Goals (MDGs) for poverty reduction unachievable. The food industries and engineering involved in food production need cleaner and safe energy to reduce this pollution.
\end{abstract}

Keywords Global warming, Pollutions, Metallic-Oxides

\section{Introduction}

There is virtually unanimous consensus among the world's scientists who work in the area of climate change that human beings are the major reason for global warming, the world's average temperature is rising because we are adding more carbon dioxide (Figure, 1) or other greenhouse gases to the atmosphere. One of the world's most widely known and respected senior scientists told the ABC News that current denial about the basic daunting realities of manmade global warming is "just foolishness"[1]. Academic and scientific surveys have repeatedly confirmed this view among the world's climate scientists. It reported that the relative climate expertise and scientific prominence of the researchers unconvinced of those tenets of climate change are substantially below that of the convinced researchers.

Climate change is the most serious challenge probably that the human race has ever confronted. Global climate change has become an important area of investigation in natural sciences and engineering. Climate change affect precipitation patterns, evapotranspiration rates, soil moisture and infiltration rates, the timing and magnitude of runoff and the frequency and intensity of storms. Subsequently, changes in evapotranspiration rates can substantially, alter rainfall-runoff processes, adding uncertainty to the understanding of important links between the hydrological cycle and ecosystems behaviour[2].

The level of atmospheric carbon dioxide $\left(\mathrm{CO}_{2}\right)$ may, also,

* Corresponding author:

p.kolawole@cgiar.org (Kolawole Oladele Peter)

Published online at http://journal.sapub.org/env

Copyright (C) 2012 Scientific \& Academic Publishing. All Rights Reserved affect both water availability and demand, through its influence on vegetation. It is nowadays widely accepted that the increasing concentration of the so-called greenhouse gases in the atmosphere is altering the Earth's radiation balance and causing the temperature to rise. This process in turn provides the context for a chain of events which leads to changes in the different components of the hydrological cycle, such as evapotranspiration rate, intensity and frequency of precipitation, river flows, soil moisture and groundwater recharge. Mankind is expected to respond to these effects by taking adaptive measures including changing patterns of land use, adopting new strategies for soil and water management and looking for non-conventional water resources (e.g. saline/brackish waters, desalinated water, and treated wastewater). All these problems will become more pronounced in the years to come, as society enters an era of increasingly complex paths towards the global economy. In this context, European and global environments are closely linked by global processes such as climate patterns, hydrological conditions and socioeconomic factors transcending regional boundaries. Consequently, achieving sustainable development in Europe will depend on the basic policies adopted by society in the decades to come. Within the Mediterranean environment, water availability and irrigation development already pose a growing problem under today's climatic conditions and anthrophic pressure and will pose even more challenges under the expected future climatic trends. The present Mediterranean climate is characterized by hot dry summers and mild wet winters. The region frequently suffers from years of scant rainfall and many areas are affected by severe drought.

They are, moreover, under various pressures to keep pace with changing needs, demands and social and economic 
development. Therefore the infrastructure in most irrigated areas (Figure 2 and 3) needs to be rehabilitated, renewed or even replaced and consequently redesigned and rebuilt, in order to meet the goal of improved sustainable production. This process depends on a set of common and well-coordinated factors, such as new advanced technology, environmental protection, institutional strengthening, economic and financial assessment, research thrust and human resources development. Most of these factors are well-known and linked to uncertainties associated with climate change[3], world prices and international trade. These uncertainties require continue attention and suitable action on many fronts, in order to promote productivity and facilitate flexibility in agricultural systems. To this end, strategies are needed to ensure maximum productivity per unit of water and land, while reducing the use of fertilizers and pesticides to improve efficiency in order to preserve the environment[4].

Food engineering involved all activities but not limited to, the application of Mechanical, Agricultural or Chemical engineering principles on food materials, it is a very wide field, and it involves the design of machinery, implementation of food safety and preservation measures. Biotechnology process of food production and design of food packaging materials are involved. Food production starts from farming, this involves cultivation of plants to yield food, feed or fibre for medicinal or industrial ingredients. Machinery is used for the production, harvesting and storage of farm crops. Crops harvested after maturity are processed into other forms. Crop processing centres depend on heat engines, a physical device that converts thermal energy to mechanical output. Heat engines run on thermodynamic cycle modelled as gasoline, turbine or steam engines. They generate heat inside the engine itself or absorb heat from an external source. They are open to the atmospheric air or sealed and closed off to the outside, but perform the conversion of heat energy to mechanical energy by exploiting the temperature gradient between a hot source and a cold sink.

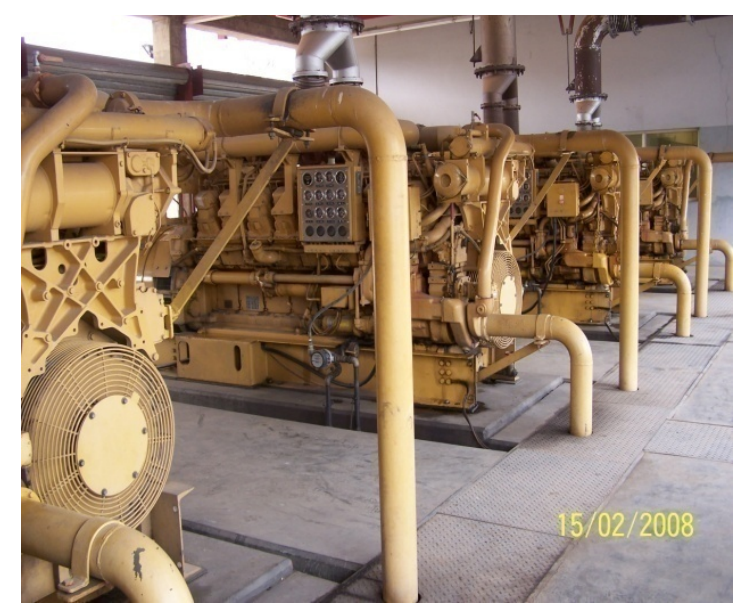

Figure 1. Generators running in ICE in food industry emitting $\mathrm{CO}^{2}$

The transfer of heat is from the source, through the working of the engine, to the sink, parts of the heats are converted into work by exploiting the properties of a working substance. All heat engines are powered by the expansion of heated gases, and the general surroundings are the heat sink, providing relatively cool gases which, when heated, expand rapidly to drive the mechanical motion of the engine. The principal constituents of the general surrounding known as atmosphere of the Earth are Nitrogen (78 per cent) and Oxygen (21 per cent). The atmospheric gases in the remaining 1 per cent are argon( 0.9 per cent), carbon dioxide( 0.03 per cent), varying amounts of water vapour, and trace amounts of hydrogen, ozone, methane, carbon monoxide, helium, neon, krypton, and xenon. In cycles and engines, the working fluids are gases and liquids from the atmosphere.

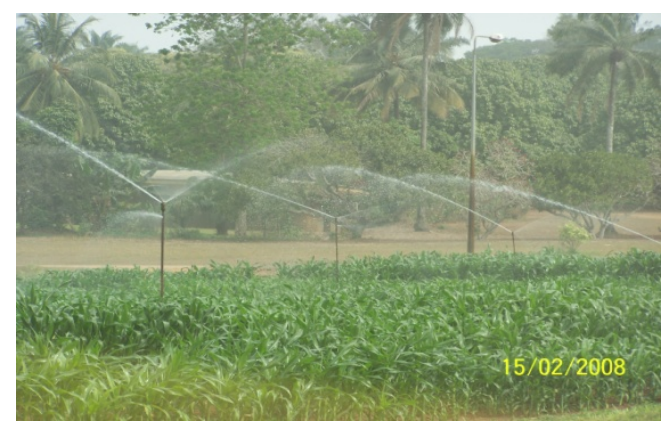

Figure 2. Irrigation replacing rainfall due to global warming

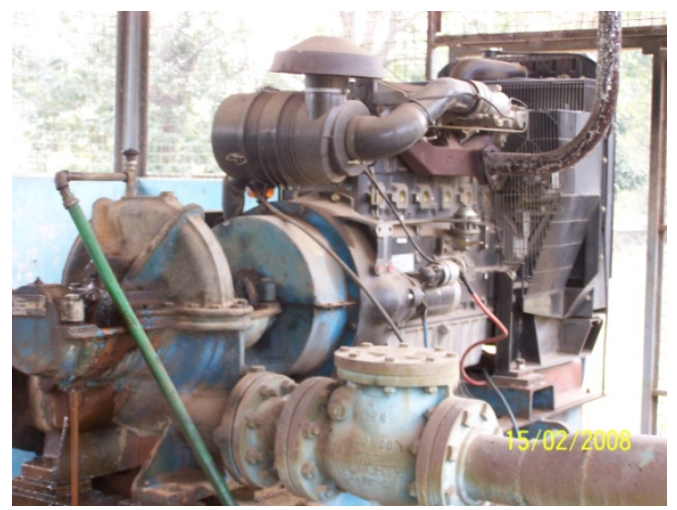

Figure 3. I CE Powered irrigation pump emitting $\mathrm{CO}^{2}$

The equipment noise and gases transferred to the atmosphere(sink) after combustion introduces contaminants into an environment. This release of contaminants to the environment is known as environmental pollution. Most of the activities generally results from human activity. These contaminants cause instability, disorder, harm and discomfort to the physical systems of living organisms. Naturally occurring substances are considered contaminants when they exceed natural levels. Adverse air quality can kill many organisms including humans[4]. Ozone pollution causes respiratory disease, cardiovascular disease, throat inflammation, chest pain, and congestion. Water pollution causes approximately 14,000 deaths per day, mostly due to contamination of drinking water by untreated sewage in developing countries[5]. Oil spills can cause skin irritations and rashes. Noise pollution induces hearing loss, high blood pressure, stress, and sleep disturbance. The major forms of 
pollution are the release of chemicals and particulates into the atmosphere. Common air pollutants include carbon monoxide, sulphur dioxide, chlorofluorocarbons (CFCs) and nitrogen oxides produced by industry and heat engines. Photochemical ozone and smog are created as nitrogen oxides and hydrocarbons react to sunlight. The release of waste products and contaminants into surface runoff, get into river through drainage systems, leaching into groundwater, liquid spills, wastewater discharges and littering. Soil contamination occurs when chemicals are released by spill or underground leakage. Among the most significant soil contaminants are hydrocarbons, heavy metals, herbicides, pesticides and chlorinated hydrocarbons[6].

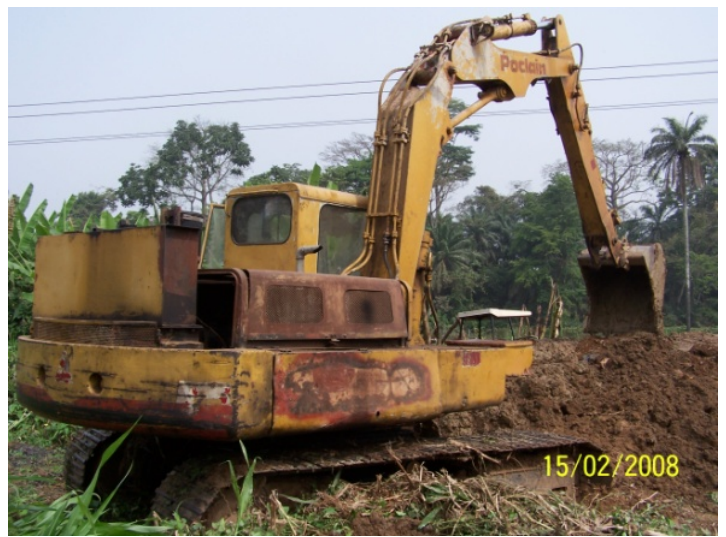

Figure 4. Excavator running on ICE creating flood drain emitting $\mathrm{CO}^{2}$

\section{Pollutants}

Principal stationary pollution sources include food chemicals, plants, coal-fired power plants, edible oil refineries, livestock farms, packaging factories and other heavy food industry. Equipment emissions are from fuel gases used in energy conversion activities. In the case of noise pollution the dominant source class is the vehicles and generators. During combustion, a large amount of reactants' chemical energy gets released in the form of thermal energy.

Today, global warming is primarily caused by $\mathrm{CO}_{2}$ emissions. A detailed combustion analysis of different fuel and technology scenarios confirm this._Burning is a complex sequence of exothermic chemical reactions between a fuel and an oxidant accompanied by the production of heat or both heat and light in the form of either a glow or flames. In a complete combustion reaction, a compound reacts with an oxidizing element, such as oxygen or fluorine and the products are compounds of each element in the fuel with the oxidizing element.

$$
\begin{gathered}
\mathrm{CH}_{4}+2 \mathrm{O}_{2} \rightarrow \mathrm{CO}_{2}+2 \mathrm{H}_{2} \mathrm{O}+\text { heat } \\
\mathrm{CH}_{2} \mathrm{~S}+6 \mathrm{~F}_{2} \rightarrow \mathrm{CF}_{4}+2 \mathrm{HF}+\mathrm{SF}_{6}+\text { heat }
\end{gathered}
$$

The combustion of hydrogen and oxygen, commonly used in rocket engines. $2 \mathrm{H}_{2}+\mathrm{O}_{2} \rightarrow 2 \mathrm{H}_{2} \mathrm{O}+$ heat. The result is simply water vapour. In the large majority of the real world uses of combustion, the oxygen $\left(\mathrm{O}_{2}\right)$ oxidant is obtained from the ambient air and the resultant gas from the combustion will contain nitrogen.

$$
\mathrm{CH}_{4}+2 \mathrm{O}_{2}+7.52 \mathrm{~N}_{2} \rightarrow \mathrm{CO}_{2}+2 \mathrm{H}_{2} \mathrm{O}+7.52 \mathrm{~N}_{2}+\text { heat }
$$

When air is the source of the oxygen, nitrogen is by far the largest part of the resultant flue gas. In reality, combustion processes are never perfect or complete. In fuel gases from combustion of carbon (as in coal combustion) or carbon compounds(as in combustion of hydrocarbons, wood etc.) both unburned carbon(as soot) and carbon compounds(CO and others) are present. Also, when air is the oxidant, some nitrogen will be oxidized to various, mostly harmful, nitrogen oxides. The problem with this stratified charge design is that after the combustion process is complete, the resulting exhaust stream contains a considerable amount of free single atoms of oxygen and nitrogen as the result of the heat of combustion splitting the $\mathrm{O}_{2}$ and $\mathrm{N}_{2}$ molecules in the air. These will readily react with each other to create Nitrous Oxide, a pollutant, in the exhaust system. Large amounts of heat and light energy are released, which often results in a fire. Combustion is double replacement reaction and chemical reaction is single replacement reaction. Combustion which takes place at low temperatures is slow. When the reactants burn in oxygen, producing a limited number of products we name it complete combustion. When a hydrocarbon burns in oxygen, the reaction will only yield carbon dioxide and water. When a hydrocarbon or any fuel burns in air, the combustion products include nitrogen. When elements such as carbon, nitrogen, sulphur, and iron are burned, they yield the most common oxides, which are the sources of pollution. It should be noted that complete combustion is impossible to achieve in reality. Actual combustion reactions come to equilibrium with a wide variety of major and minor species. The combustion of methane in air yields in addition to the major products of carbon dioxide and water, the minor products such as carbon monoxide, hydroxyl, nitrogen oxides, monatomic hydrogen, and monatomic oxygen.

Turbulent combustion characterized by turbulent flows is the most used in food and other industries for industrial application (e.g. gas turbines, diesel engines, etc.) because the turbulence helps the mixing process between the fuel and oxidizer. Incomplete combustion occurs when there isn't enough oxygen to allow the fuel (usually a hydrocarbon) to react completely with the oxygen to produce carbon dioxide and water, also when the combustion is quenched by a heat sink such as a solid surface or flame trap. Scavenging of pushing exhausted gas-charge out of the cylinder of engine and drawing in a fresh draught of air ready for the next cycle in automotive usage. Smouldering combustion is from heterogeneous reactions occurring on the surface of a solid fuel.

The burning of hydrocarbon in sufficient oxygen minimises pollution. The simple word equation for the combustion of a hydrocarbon in oxygen is:

Fuel + Oxygen $\rightarrow$ Heat + Water + Carbon dioxide

The simple word equation for the combustion of a hydrocarbon in air is:

Fuel + Air $\rightarrow$ Heat + Water + Carbon dioxide + Nitrogen $(8)$

A multi-fuel technology that mixes diesel with other fuel sources could cut $\mathrm{CO}_{2}$ (greenhouse gas) emissions from heavy-goods vehicles(HGVs)(9). 


\section{Pollution Controlling}

Los Angeles, in 1947, was the first place to call attention to atmospheric pollution problems, which in 1952, Dr. Arie J. Haagen-Smit blamed the rise on the automobile, which was backed by his research. In a complete combustion process, for every kilogram of hydrocarbon fuel burnt, $1.3 \mathrm{~kg}$ of $\mathrm{H}_{2} \mathrm{O}$ and $3.1 \mathrm{~kg}$ of $\mathrm{CO}_{2}$ is produced[8]. The undesirable exhaust emissions, Nirogen Oxides, $\mathrm{HC}, \mathrm{CO}, \mathrm{CO}_{2}$, Polyaromatics, soots, lead salts, nitro-olefines, and aldehydes ketones, are produced in very small quantities, only Oxides of Nitrogen, $\mathrm{HC}$, and $\mathrm{CO}$ is produced in large quantities enough to cause environmental problems. $\mathrm{CO}_{2}$ caused concerns because it was suspected of allowing ultra-violet rays to penetrate the atmosphere. $\mathrm{CO}$ causes problems by being absorbed into red corpuscles of the blood, preventing the absorption of oxygen. Nitric acids and nitrogen dioxide along with $\mathrm{HC}$ caused smog.

The first method used for controlling emissions produced by the heat engines was to have precise control over the carburettor or fuel injection system; this provides accurate mixtures of fuel and air for complete combustion. During idling, the fuel mixture could either made to be completely combustible, or was cut off. Devices that were sensitive to manifold pressure, tapped immediately downstream of the throttle, could be employed to retard the ignition during slow engine speeds. Gulp valves may be produced to compensate for the lack of air when the throttle is suddenly closed, allowing for the fuel to be completely combusted. High temperature thermostats can be employed to improve cold weather combustion. Positive crankcase ventilation may be employed to eliminate the crankcase fumes. To combat the problems with Nitrogen Oxides, exhaust gas recalculation can be used to lower the temperature of combustion. This additional step had to be placed before the oxidation of $\mathrm{HC}$ and $\mathrm{CO}$ because of the needs to reduce atmosphere call for a rich mixture. For this, a closed loop system employed was to regulate the supply of fuel accurately according to the incoming air mass, which can be accomplished with the lambda sensor.

The evaporative emissions are mostly composed of Hydro Carbons, generally from fuel tank venting system, carburettor venting system, permeation through plastic tanks, and through the crankcase vent. To combat the fuel tank vent problems, a carbon canister was employed to catch the exiting fumes, and periodically cleaned.

The permeation through the tank walls is solvable with one of several methods: sulphur trioxide treatment, fuel system lamination, fluorine treatment, or injection moulding. All of these methods act as barriers that successfully block the emissions. From the total hydro-carbon HC pollution, the crankcase used to account for 25 percent of the total. To prevent this source of toxins, the crankcase fumes were vented into the induction manifold through a close circuit by a positive ventilation system. Then the excess $\mathrm{HC}$ is allowed to burn in the combustion process in the cylinder. The positive flow is provided through a venting system into the cyl- inder heads, which is capped off with an air filter. In order to prevent the back flow of the $\mathrm{HC}$ fumes, a valve is employed to stop back flow, limit suction in the crankcase, and lastly to avoid upsetting the flow at slow engine speeds. Additional parts have been employed to reduce emissions, such as the gulp valve. The gulp valve is used to account for conditions such as a sudden release of the throttle. In a situation like this, the fuel mixture momentarily is still delivered to the engine, but the air needed for complete combustion is taken away. The gulp valve is used to provide the necessary additional air to allow for the complete combustion of the fuel, thereby reducing emissions.

\section{Preventing Pollution}

Air Fuel Ratio (AFR) is an important measure for anti-pollution and performance tuning reasons. In food industries fired heaters, power plant steam generators, and large gas-fired turbines, are common, the use of excess combustion air of 15 percent would means that 15 percent more than the required stoichiometric air is being used. A stoichiometric mixture is the working point that modern engine management systems employed to achieve in light load situations. The air fuel ratio is the most common reference term used for mixtures in internal combustion engines, the ratio between the mass of air and the mass of fuel in the fuel-air mix at any given moment. FAR is frequently used in government studies of internal combustion engine and refers to the ratio of fuel to the air, it is 1/AFR.

Heat engine emissions control covers all the technologies that are employed to reduce the air pollution-causing emissions by heat engines. Emissions controls have been highly successful in reducing the emissions produced by engines in terms of quantity. The emissions produced fall into three basic categories

\subsection{Exhaust Emissions}

This is what most people think of when they think of heat engines air pollution; the products of burning fuel in the engine, emitted from the exhaust system. Hydrocarbons are made up of unburned or partially burned fuel, and are a major contributor to urban smog, as well as being toxic. They can cause liver damage and even cancer. Nitrogen oxides are generated when nitrogen in the air reacts with oxygen under the high temperature and pressure conditions inside the engine. These emissions contribute to both smog and acid rain. Carbon monoxide(CO) is a product of incomplete combustion, carbon monoxide reduces the blood's ability to carry oxygen and is dangerous to people with heart disease. Carbon dioxide $\left(\mathrm{CO}_{2}\right)$, although this is a product of the complete combustion of hydrocarbons, is plentiful in the atmosphere, has no immediate harmful effects to humans and is essential to plant life, emissions of carbon dioxide are considered a pollutant because it is a significant greenhouse gas and increasing its levels in the atmosphere contributes to global climate change. (Data on 
$\mathrm{CO}_{2}$ emissions from fuel combustion by International Energy Agency's is available athttp://www.iea.org/co2highl ights/co2Highlights.XLS)

\subsection{Evaporative Emissions}

These are produced from the evaporation of fuel, and are a large contributor to urban smog, since these heavier molecules stay closer to ground level. Fuel tends to evaporate in these ways. Gas tank venting gasoline as the tank evaporates. The heating of the vehicle as the temperature rises from the night-time temperature to the hottest temperatures of the day mean that, increasing the pressure inside the tank above atmospheric pressure. This pressure must be relieved, and before emissions control it was simply vented into the atmosphere. Running losses are those gasolines that escape as vapours from the hot engine. These can cause a lot of hydrocarbon vapour emission. The empty space inside a fuel tank is filled with hydrocarbon gases, and as the tank is filled, these gases are forced out into the atmosphere. In addition, there is loss from further evaporation and fuel spillage. Advances in engine continually reduce the amount of pollutants generated, but this is generally considered insufficient to meet emissions goals. Therefore, technologies to react with and clean up the remaining emissions have long been an essential part of emissions control.

\subsection{Air Injection}

A very early emissions control system, the Air injection reactor (AIR) reduces the products of incomplete combustion (hydrocarbons and carbon monoxide) by injecting fresh air into the exhaust manifolds of the engine. Efforts at the reduction of evaporative emissions include the capturing of vented vapours from within the vehicle, and the reduction of refuelling emissions. Within the engine, vapours from the fuel tank are channelled through canisters containing activated carbon instead of being vented to the atmosphere. The vapours are adsorbed within the canister, which feeds into the inlet manifold of the engine. When the engine is running, the vapours desorbs from the carbon, are drawn into the engine and burned.

Reducing refuelling losses designs were included in all modern equipment. Tank filler necks now have a smalldiameter hinged and spring-loaded door only large enough for the tip of the filler nozzle. This prevents vapour leakage when the filler cap is removed, and also prevents a catalytic converter-fitted engines being refuelled with leaded fuel (since the leaded fuel nozzle is too large to fit).

This is accompanied by modifications to the filling station pumps. They are now equipped to suck the vapours back into the pump as they are displaced by fuel. Some have intakes around the head of the filler nozzle, while others have a rubber 'boot' that presses securely around the end of the filler neck to prevent vapours escaping.

Exhaust gas recirculation (EGR) is a nitrogen oxide and nitrogen dioxide reduction technique used in most gasoline and diesel engines. EGR works by recirculation of a portion of an engine's exhaust gas back to the engine cylinders. Intermixing the incoming air with re-circulated exhaust gas dilutes the mix with inert gas, lowering the adiabatic flame temperature and (in diesel engines) reducing the amount of excess oxygen. The exhaust gas also increases the specific heat capacity of the mix lowering the peak combustion temperature. Because Nitrogen oxides formation progresses much faster at high temperatures, EGR serves to limit the generation. Nitrogen oxide is primarily formed when a mix of nitrogen and oxygen subjected to high temperatures. EGR in spark-ignited engines: in a typical automotive spark- ignited (SI) engine, 5 to 15 percent of the exhaust gas is routed back to the intake as EGR (thus comprising 5 to 15 percent of the mixture entering the cylinders). The maximum quantity is limited by the requirement of the mixture to sustain a contiguous flame front during the combustion event; excessive EGR in an SI engine can cause misfires and partial burns. Although EGR does measurably slow combustion, this can largely be compensated for by advancing spark timing. Contrary to popular belief, a properly operating EGR actually increases the efficiency of gasoline engines via several mechanisms.

Reduced throttling losses, the addition of inert exhaust gas into the intake system means that for a given power output, the throttle plate must be opened further, resulting in increased inlet manifold pressure and reduced throttling losses.

Lowered peak combustion temperatures not only reduce Nitrogen oxide formation, it also reduces the loss of thermal energy to combustion chamber surfaces, leaving more available for conversion to mechanical work during the expansion stroke. The lower peak temperatures result in more of the released energy remaining as sensible energy near TDC, rather than being bound up(early in the expansion stroke) in the dissociation of combustion products. This effect is relatively minor compared to the first two. In modern diesel engines, the EGR gas is cooled through a heat exchanger to allow the introduction of a greater mass of re-circulated gas. Unlike SI engines, diesels are not limited by the need for a contiguous flame front; furthermore, since diesels always operate with excess air, they benefit from EGR rates as high as 50\%(at idle, where there is otherwise a very large amount of excess air) in controlling emissions.

\section{Challenges}

Climate change has started to affect weather patterns, sea levels, seasons, and both glacial and polar ice. The global weather system is threatening to spin out of control (Figure 5). For people this means that seasons become unpredictable, farming becomes riskier, freshwater supplies become unreliable, storms and rising sea levels threaten to take away whole islands and coastal areas.

Doom days was predicted by some agricultural scientists regarding the catastrophic consequences of global warming[10]. On the face of it the logical deductions made appear to be worth considering seriously. In search for solution 
Radioactive-Convective model of the earth-atmosphere system was used to investigate the cooling effects induced by sulphur injections into the stratosphere[11]. Several reengineered scenarios were analysed[12]. Surface air temperature anomalies induced by stratospheric sulphate aerosol generated[13] compensate future warming[14]. Continuous deployment of sulphur into the stratosphere could induce a lasting decrease in surface air temperature[15]. Further, examinations were conducted to see if the pollution, particularly of nitrogen and phosphates (often associated with cultivations and use of mineral fertilizers) could be reduced or eliminated, so as to be able to develop systems which could contribute to the reversal of global warming.

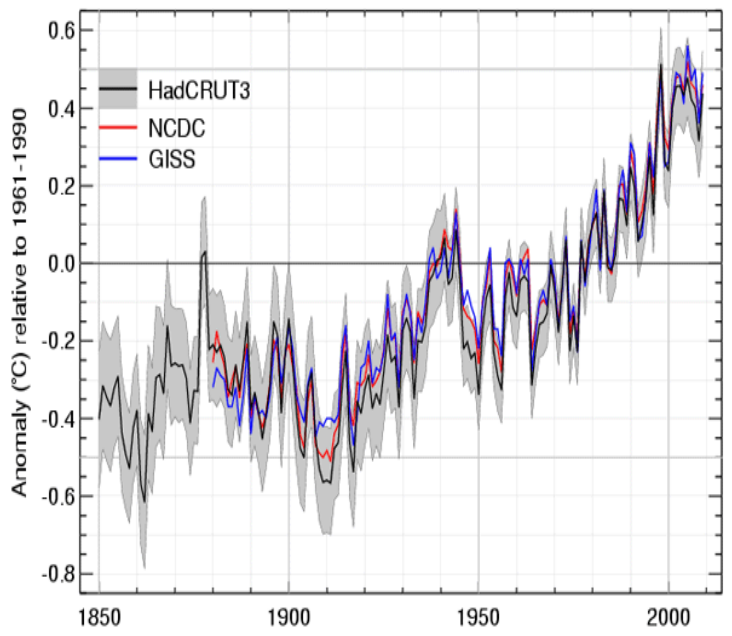

Figure 5. Global temperature 1850-2008 Average annual surface temperature, based on measurements by meteorological stations, ships and satellites, as reported independently by three different groups: NOAA $(N C D C)$ and NASA $(G I S S)$ in the US, and the combined Hadley Centre and Climate Research Unit of the University of East Anglia in the UK ( $\mathrm{Had}$ CRUT3). Source: World Meteorological Organization

The design modifications alone in automotive engineering cannot solve the problem. Will switching from polluting fossil fuel based energy systems to clean energy solve these problems? Fossil fuels have the biggest historical and present share of polluting emissions. This development in industries of industrialized countries as well as in less-developed countries contributes to global warming.

Firewood consumption has led to severe deforestation and desertification in Africa. Because regional sources have become scarce, highly efficient wood stoves alleviate this problem by saving about $80 \%$ of the firewood. The stoves can work day and night and do not require a shift of cooking habits. 2.7t of $\mathrm{CO}_{2}$ are saved per stove annually. This is the equivalent of a plane-trip Frankfurt-Dakar (return)[16]

\section{Conclusions}

Since the industrial revolution, humans have been emitting greenhouse gases that the Intergovernmental Panel on Climate Change (IPCC) believes are responsible for global warming. There have been more environmental refugees than at any other time. Attempts made to correct global warming crates more pollutants as Internal Combustion Engines (ICE) add more $\mathrm{CO}^{2}$. Global warming is already happening. Its impact is being felt mostly by the world's poorest people. Field observations are in progress this will be published as soon as possible. Food production, water supplies, public health, and people's livelihoods are all being damaged and undermined. It threatens to reverse human progress. It seems as if the United Nations' Millennium Development Goals (MDGs) for poverty reduction may not be unachievable. Climate change, if left unchecked now will drive these incidents out of control.

Engineers in the food industry may have to ignore those suggestions that the IPCC's climate models might not be correct. The world need prove that food engineering activities do not lead to Global warming. Majority of climatologists agree with the IPCC's conclusions.

\section{Recommendations}

Food engineers must prove that emissions generated during those activities can not cause global warming or stop completely all environmental contamination. The sources must be regulated by each country. Adequate use of available solution must be encouraged. Effective strategies that will enhance the livelihood opportunities of the rural poor must be sustained for the ecosystem services[17]. Engineers in food industries must be able to achieve sufficient scale to have a broad effect designed to increase economic, social, and ecological resilience to climate change.

Food processors need to adopt the use of clean energy to prevent the face of global warming. New form of energy development and nature conservation that are climate friendly are needed.

Food engineers need new devices that must pass the test of weather by reducing emissions. Small-scale renewable energy are needed in food industries and community groups to tackle and reduce climate change. These require political commitments and fund from governments in all countries. A major shift in priorities by development bodies, as well as re-directing private investment will help (18).

To stop these climate changes from running out of control, the world needs to keep global average warming lower than pre-industrial levels. Emissions of $\mathrm{CO}_{2}$ and other greenhouse gases by industrialized countries must be cut on the order. Industrialized countries have an obligation to take a lead in climate change mitigation and adaptation, and to bear an equitable burden of the associated costs.

Food industry engineers need to:

1. Look for ways to reduce emissions, as obligations for its reduction under the Kyoto Protocol, the world's only legal multilateral base for action to contain climate change[18].

2. Develop renewable efficient energy for use in the industry.

3. Food industries need to be with zero-emission if possible.

4. Governments in developing countries must enforce 
forests conservation laws.

5. Use of firewood for cooking and processing food in bakeries must stop.

6. Effective ways of adapting global warming prevention must be encouraged in the food industry.

7. The introduction of pollution prevention and control legislation for the food and drink industry should include enforcement of those engineering devices that can reduce the contaminants in the whole world.

8. Low-carbon technologies must be encouraged to drive the process to clean energy.

9. All global industrial sites within the catchment size must obtain licences.

10. Effluent waters must be treated before discharge.

\section{REFERENCES}

[1] Blakemore B.(2012) Global Warming Denialism 'Just Foolishness http://abcnews.go.com/blogs/ technology/2012/0 4/global-warming-denialism-just- foolishness-scientist-peterraven-says/

[2] Butterworth, William R. 2009. "The Technology of Waste, Biofuels and Global Warming in Viable Closed Loop, Sustainable Operations." Energies 2, no. 4: 1192-1200.

[3] Butterworth, B. Relevant Technology. In Reversing Global Warming for Profit; MX Publishing: London, UK, 2009; pp. $40-44$.

[4] EPA,(1988) Environmental Protection Agency, and the Inside Story: A Guide to Indoors Air Quality(Washington, DC),

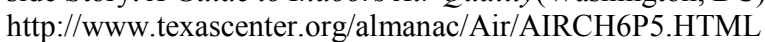

[5] Pidot, J. R.(2006). Global Warming in the Courts - An Overview of Current Litigation and Common Legal Issues. Georgetown University Law Center.

[6] Shiklomanov, I. A.(2000). Appraisal and Assessment of World Water Resources, Water International 25(1): 11-32.

[7] Garrett W.; Balich; Conrad R. and Aschenbach(2004). The
Gasoline 4-Stroke Engine for Automobiles Department of Aerospace and Mechanical Engineering, University of Notre Dame Notre Dame, IN 46556

[8] Newton, K.; Garrett T. K. and Steeds W.(2001). The Motor Vehicle, 13th Edition. SAE International, Warrendale, PA.

[9] Shead S.(2012). Multi-fuel technology could reduce emissions from HGVs http://www.theengineer.co.uk/101226 2.article?cmpid=TE01

[10] Potty V. H.(2011) Global warming, Basmati Rice- India to lose dominance http://foodtechupdates.blogspot.com http://vhpotty.blogspot.com/

[11] Rasch, P.J.; Tilmes, S.; Turco, R.P.; Robock, A.; Oman, L.; Chen, C.C.; Stenchikov, G.L.; Garcia, R.R.( 2008) An overview of geoengineering of climate using stratospheric sulphate aerosols. Phil. Trans. Roy. Soc. A-Math. Phy. 366, 4007-4037

[12] Matthews, H.D.; Cao, L.; Caldeira, K.(2009) Sensitivity of ocean acidification to geoengineered climate stabilization. Geophys. Res. Lett., 36, L10706.

[13] Moore, J.C.; Jevrejeva, S.; Grinsted, A.(2010) Efficacy of geoengineering to limit 21 st century sea-level rise. Proc. Natl. Acad. Sci USA. 107, 15699-15703.

[14] Bala, G.; Duffy, P.B.; Taylor, K.E.(2008) Impact of geoengineering schemes on the global hydrological cycle. Proc. Natl. Acad. Sci USA, 105, 7664-7669.

[15] Goes, M.; Tuana, N.; Keller, K.( 2010) The Economics(or lack thereof) of Aerosol Geoengineering. Climatic Change, in review.

[16] FAO(2010). The millennium development Goals and climate change: taking stock and looking ahead http://www.fao.org/f ilead$\mathrm{min} /$ user_upload/rome2007/docs/MDGs\%20\&\%20CC.pdf pp15-28 http://www.atmosfair.de

[17] United Nations Development Programme(UNDP). 2010. The Local Capacity Strategy: Enabling Action for theEnvironment and Sustainable Development. New York: UNDP.

[18] Global Warming Pollution Reduction Act(2007). http://www.opencongress.org/bill/110-s309/show 